\title{
Management of Chronic Diarrhea in Primary Care: The Gastroenterologists' Advice
}

\author{
Heinz F. Hammer \\ Division of Gastroenterology and Hepatology, Department of Internal Medicine, Medical University Graz, Graz, \\ Austria
}

\section{Keywords}

NET · Celiac disease · Inflammatory bowel diseases .

Treatment · Diagnosis

\begin{abstract}
Background: Chronic diarrhea is defined as more than 3 bowel movements per day, or loose stools, or stool weight $>200 \mathrm{~g} /$ day for at least 4 weeks. Accompanying symptoms may include urgency, abdominal pain, or cramps. Summary: A number of causes have to be considered, including inflammatory, neoplastic, malabsorptive, infective, vascular, and functional gastrointestinal diseases. Other causes include food intolerances, side effects of drugs, or postsurgical conditions. Diarrhea may also be symptom of a systemic disease, like diabetes or hyperthyroidism. Special patient groups, like the very elderly and immunocompromised patients, pose special challenges. This review follows a question-answer style and addresses questions raised on the intersection of primary and secondary care. What do you mean by diarrhea? Why is it important to distinguish between acute or chronic diarrhea? How shall the patient with chronic diarrhea be approached? How can history and physical exam help? How can routine laboratory tests help in categorizing diarrhea? Which additional laboratory tests may be helpful? How to proceed in undiagnosed or intractable diarrhea? What are
\end{abstract}

karger@karger.com www.karger.com/ddi

Karger!"

GOPEN ACCESS
(C) 2021 The Author(s)

Published by S. Karger AG, Basel

This is an Open Access article licensed under the Creative Commons Attribution-NonCommercial-4.0 International License (CC BY-NC) (http://www.karger.com/Services/OpenAccessLicense), applicable to the online version of the article only. Usage and distribution for commercial purposes requires written permission. the treatment options in patients with chronic diarrhea? Key Messages: Acute diarrhea is usually of infectious origin with the main treatment goal of preventing water and electrolyte disturbances. Chronic diarrhea is usually not of infectious origin and may be the symptom of a large number of gastrointestinal and general diseases or drug side effects. In undiagnosed or intractable diarrhea, the question shall be raised whether the appropriate tests have been performed and interpreted correctly.

(C) 2021 The Author(s)

Published by S. Karger AG, Basel

\section{Introduction}

Chronic diarrhea is defined as more than 3 bowel movements or loose stools for at least 4 weeks $[1,2]$. Population-based studies have suggested a prevalence of chronic diarrhea in the USA between 14 and 18\% [3]. Symptoms which may accompany chronic diarrhea may include urgency, abdominal pain, or cramps with bowel movements. Several conditions may be responsible for chronic diarrhea, including inflammatory [4], neoplastic [5], malabsorptive [6-8], infective [9, 10], and functional gastrointestinal diseases [11]. Other causes include food intolerances $[12,13]$, side effects of drugs like magnesium $[14]$ or promotility drugs [15], or postsurgical $[6,16]$ con- 
ditions. Diarrhea may also be a symptom of a systemic disease, like diabetes [17, 18] or hyperthyroidism [19]. Special patient groups, like the very elderly and the immunocompromised patients pose special challenges in the diagnosis and treatment of chronic diarrhea [10].

Chronic diarrhea may result in a multitude of clinical and social problems for the patients. The most frequent causes of diarrhea are functional [11] and have neither life-threatening consequences nor are they sign of a severe underlying disease, although chronic diarrhea may severely inflict on quality of life [20-23], due to interference of diarrhea, fecal urgency, or fecal incontinence with normal daily activities. In a proportion of patients, chronic diarrhea is symptom of a disease, like in inflammatory bowel diseases (IBD); and in these patients, other symptoms, like blood loss or abdominal pain, may have more clinical relevance than diarrhea [4]. In a small minority, chronic diarrhea can be life-threatening, due to excessive fluid and electrolyte losses, for example, in some endocrine tumors $[5,20]$ or in surreptitious abuse of laxatives or diuretics [20-22].

This review will focus on clinical questions which arise at the transition between primary and secondary care of patients with chronic diarrhea and are based on clinical experience of the author in this clinical situation. The review is not designed to replace a comprehensive guideline, for this the reader is referred to the British society guideline [23] or the AGA technical review on diarrhea [2]. For review of additional specific clinical questions, the reader is referred to articles on the value of stool analysis [24] and colorectal histopathology [25] and articles on diarrhea in celiac disease [26] and on antibiotic-associated diarrhea [27].

To stay close to clinical relevance, this review is structured along questions which may be raised by patients or primary care physicians. Although this review represents the subjective view and interpretation of literature and personal experiences of the author, the wording used for the recommendations leans on wording used for guidelines [28] with high strength of recommendation indicated by wordings like "has to be," "is to be," or" shall"; moderate strength indicated by "should" or "can"; low strength by "could"; and very low strength indicated by "may."

\section{What Do You Mean by Diarrhea?}

Adherence to a definition of diarrhea is a prerequisite to avoid misunderstanding and misinterpretations. Diarrhea is defined by 3 criteria: stool frequency ( $\geq 3$ bowel movements per day), stool consistency (soft, mushy, or watery),
Table 1. Medications and toxins to be considered as a cause of diarrhea (modified after [42])

Acid-reducing drugs and antacids

Anti-arrhythmics

Antibiotics

Antihypertensives (beta-blockers)

Antineoplastic drugs

Antiretroviral drugs

Colchicine

Heavy metals

Herbal products

NSAID

Prostaglandin analogs

Theophylline

Vitamin and mineral supplements

NSAID, nonsteroidal anti-inflammatory drug.

and stool weight ( $<200 \mathrm{~g} /$ day) [2]. Either one of these 3 criteria is enough to define diarrhea clinically. However, in the view of patients, it is usually increased fluidity and/or frequency of stools which is of concern, and in fact, fecal weight may be higher than $200 \mathrm{~g} /$ day in healthy persons if the fiber content of meals is high. Accompanying symptoms like pain with defecation or fecal urgency may be additional or leading features which are bothersome to patients. A hidden symptom, which commonly is not volunteered by patients at their first consultation, is fecal incontinence. Last, fecal evacuations with high stool weight may occur without the patient recognizing it as diarrhea in cases of severe malabsorption due to exocrine pancreatic insufficiency when because of a high fecal fat content [6], consistency of stool [29] is not decreased.

Stool weight in diarrhea may be clinically important to measure if there is concern about balancing fluid and electrolyte losses due to diarrhea $[14,24]$. However, only in a minority of patients referred to a highly specialized center, daily stool weight was higher than $500 \mathrm{~g} /$ day, and only few patients had a stool weight beyond $1,000 \mathrm{~g} /$ day, representing losses of isotonic fluids in excess of $1 \mathrm{~L}$ [24].

\section{Why Is It Important to Distinguish between Acute or}

\section{Chronic Diarrhea?}

The distinction between acute and chronic diarrhea is more than semantics. It is an important clinical distinction relevant for diagnostic approach and treatment options $[23,30]$.

Acute diarrhea is of a duration less than 4 weeks and is usually of infectious causes (bacterial, viral, and parasites) or drug induced (see Table 1). Special circumstances like 
recent travel or an immunocompromised state may require consideration. Clinically, systemic complications due to dehydration, electrolyte disturbances, and rarely sepsis or Guillain-Barre syndrome may require attention [31]. Diarrhea may become clinically relevant as a nursing problem [32] or it may develop into a nuisance (e.g., in travel).

Treatment of acute diarrhea is usually symptomatic, including, but not restricted to, oral or intravenous water and electrolyte replacement or of the underlying pathogen. Symptomatic treatments with, among others, loperamide or the enkephalinase inhibitor racecadotril (100 mg up to 3 times daily) may be useful [30].

Chronic diarrhea in developed countries is commonly the symptom of a large number of noninfectious intestinal and extraintestinal diseases $[2,33]$ although there are a few infectious causes that have to be considered, like Clostridioides difficile [27], or Giardia lamblia, ameba or other pathogens in people having returned from travel into the subtropic regions [34]. Chronic diarrhea may be accompanied by malabsorption and by a variety of symptoms of the underlying cause of diarrhea. The prognosis usually depends on the underlying disease, and the treatment is directed against the underlying disease, if possible, or shall be symptomatic [2].

\section{How Should the Patient with Chronic Diarrhea Be Approached?}

With a large differential diagnosis of potential causes of diarrhea, the clinical challenge is not to overdo or repeat diagnostic tests in the face of the frequently occurring functional causes of diarrhea and at the same time, not to overlook diseases which demand specific treatments or may be dangerous and therefore must not be overlooked to prevent complications or delayed damage. The clinically important questions related to this are as follows:

1. Is symptomatic therapy appropriate to start with?

2. For how long may symptomatic treatment be given and how to follow up on it?

3. How may the tests which are available in primary care practice help?

4. For which patient is a referral for further information required?

\section{How Can History and Physical Examination Help?}

Alarm symptoms, also called red flag symptoms, may be helpful in identifying patients with abdominal symptoms who have a risk of relevant diseases like GI cancer, IBD, or malabsorptive diseases and therefore may guide
Table 2. Likely causes of diarrhea in well-defined patient groups or clinical settings (modified after [42])

Travelers

Bacterial infections (mostly acute diarrhea)

Protozoal infections (ameba and giardia lamblia)

Tropical sprue

Epidemics

Bacterial infection

Viral infections

Rare causes

Diabetic patients

Autonomic neuropathy

Drug side effects (acarbose and metformin)

Fructose malabsorption

Associated diseases: celiac, pancreatic insufficiency, and SIBO

Immunodeficiency

Opportunistic infections

Drug side effects

Lymphoma

Institutionalized persons

Clostridioides difficile

Drug side effects

Fecal impaction with overflow diarrhea

Ischemic colitis

Tube feeding

SIBO, small intestinal bacterial overgrowth.

physicians toward further diagnostics in patients with abdominal symptoms [35]. These alarm symptoms are blood in stool, awakening by symptoms, unintended weight loss, family history of gastrointestinal cancer, or symptom onset after the age of 50 years. However, positive predictive values for each of these alarm symptoms for any of the above named relevant diseases are below $10 \%$ so that patients should not be alarmed too much if one of these red flags are noticed [35]. In contrast, alarm symptoms may occur in functional diarrhea or IBS with a frequency of up to $18 \%$ for blood in stool, up to $51 \%$ for awakening because of symptoms, up to $33 \%$ for unintentional weight loss, and $40 \%$ for symptom onset beyond the age of 50 years. Furthermore, up to $20 \%$ of patients with functional diarrhea or IBS may have a positive family history of gastrointestinal cancer [35]. Therefore, alarm symptoms do not exclude a functional cause of diarrhea. History shall also focus on medications and toxins associated with diarrhea (Table 1) and in identifying likely causes of diarrhea in well-defined patient groups (Table 2).

Physical exam of the abdomen may reveal localized tenderness or masses which shall direct attention away from functional causes of diarrhea and serve as an argu- 
ment for further diagnostic evaluations. Measurement of blood pressure and heart rate and inspection of mucous membranes may help to detect anemia or dehydration.

\section{How Can Routine Laboratory Tests Help?}

Laboratory tests which are commonly available to primary care may be helpful in detecting the presence of accompanying symptoms or complications of diarrhea. Detection of accompanying symptoms may guide the direction of the further diagnostic evaluations. These are the detection of bleeding through decreased red cell counts and fecal occult blood, detection of inflammatory processes by elevated white blood cell counts, elevated platelet counts in Crohn's disease, sedimentation rate or CRP, or signs of malabsorption (of iron or vitamin $\mathrm{B}_{12}$ or vitamin K) through altered mean corpuscular volume or hemoglobin content of the erythrocytes and increased prothrombin time. Fluid and electrolyte losses may be assessed with serum creatinine, serum $\mathrm{Na}$ and $\mathrm{K}$ concentrations, and urinary volume and concentration. In the case of abdominal pain, serum amylase or lipase, urinary analysis, and cholestasis parameters may be of additional help.

\section{Which Additional Laboratory Tests May Be Helpful?}

Some specialized laboratory tests may be used by primary care physicians in their further diagnostic evaluations. Samples for these tests can be collected in the physician's office to be sent to specialized laboratories for analysis. These tests are the analysis of serum samples for tissue transglutaminase for the diagnosis of celiac disease in malabsorption and of chromogranin $\mathrm{A}(\mathrm{CgA})$ for the diagnosis of rare neuroendocrine tumors in the case of watery diarrhea. Fecal samples can be sent for analysis of calprotectin if IBD is suspected, elastase if exocrine pancreatic insufficiency is suspected, and Clostridioides difficile if there is a history of antibiotic use.

Sensitivity of immunoglobulin A-tissue transglutaminase for the detection of celiac disease ranges between 78 and $100 \%$, with a specificity between 90 and $100 \%$ [36]. Positive serology should be supported by histology obtained from the duodenum.

Sensitivity of CgA in patients with secreting neuroendocrine tumors of all locations is around $70 \%$ and is 80 $100 \%$ for carcinoid tumors [37]. Falsely elevated CgA levels may occur in renal insufficiency, atrophic gastritis, heart insufficiency, and proton-pump inhibitor treatment. Positive results shall be further evaluated by neuroendocrine tumor search tests, like octreotide scintigraphy or positron emission tomography-CT scanning $[38,39]$.
The presence of calprotectin in feces is directly proportional to neutrophil migration to the gastrointestinal tract. It is very sensitive for inflammation but not specific regarding the cause of inflammation [40]. Only markedly elevated calprotectin levels are indicative of IBD, whereas less pronounced elevations may also occur in diarrheapredominant IBS. A recent study (upper limit of normal for fecal calprotectin was $50 \mu \mathrm{g} / \mathrm{g}$ feces) has demonstrated a mean calprotectin concentration in IBS of approximately $100 \mu \mathrm{g} / \mathrm{g}$ feces with individual values up to 800 , whereas mean concentrations in IBS where approximately $1,000 \mu \mathrm{g} / \mathrm{g}$ [41]. Elevated calprotectin levels shall be further evaluated by colonoscopy.

Fecal elastase concentrations below $100 \mu \mathrm{g} / \mathrm{g}$ feces have a sensitivity of $54 \%$ for mild and $95 \%$ for severe exocrine pancreatic insufficiency and a specificity between 79 and $96 \%$ [42]. Low levels shall be further evaluated by $\mathrm{CT}$ scan of the pancreas in order to demonstrate signs of chronic pancreatitis and to exclude pancreatic duct obstruction due to tumor of the papilla or the pancreatic head.

\section{How to Proceed in Undiagnosed or Intractable Diarrhea?}

Some patients with chronic diarrhea may return to primary care after specialized diagnostic evaluations with undiagnosed or intractable diarrhea. These are patients not having responded to seemingly appropriate treatment with diet, probiotics, adstringents, opioids, and others. In these patients, commonly most appropriate tests have been performed, including laboratory tests of serum and stool, endoscopic evaluations of the upper and lower GI tract, ultrasound, and radiographic examinations.

Clinical challenges in undiagnosed or intractable diarrhea may include that:

1. no pathology or disease has been identified,

2. pathology has been identified but its clinical role remains uncertain,

3. results of clinical testing may have led into a wrong direction,

4. treatment has been ineffective or inappropriate, and

5. expectations on establishing a diagnosis or curing the disease have been too enthusiastic.

In these patients, the following questions must be raised and appropriately dealt with:

1. Have the appropriate tests been performed and interpreted correctly?

2. Which test results must be reevaluated?

3. Are additional tests worth doing?

4. Are tests leading down the wrong alley? 
Table 3. Treatment options in chronic diarrhea (modified after [42])

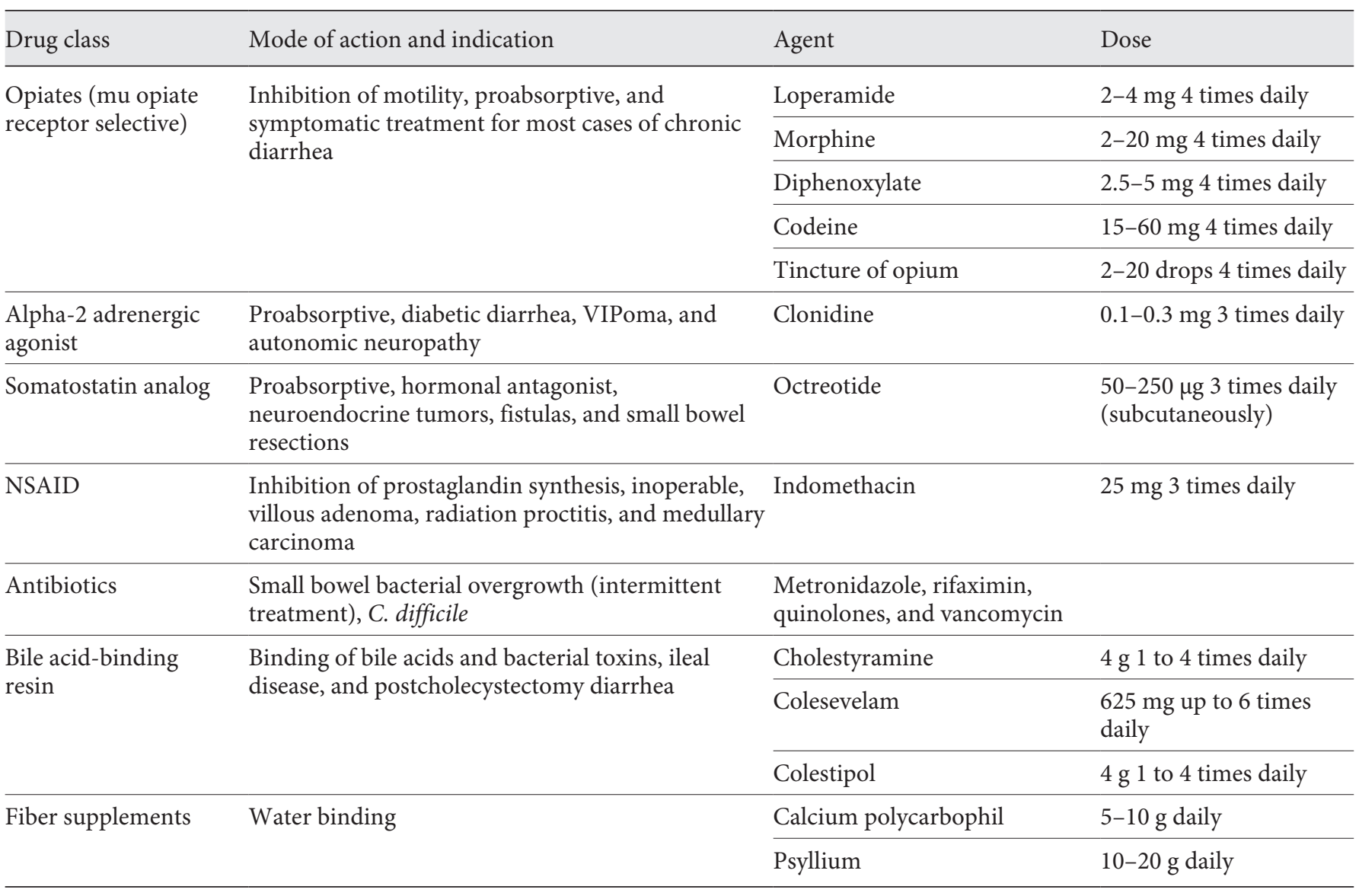

NSAID, nonsteroidal anti-inflammatory drug.

5. Shall treatments beyond the routine be considered?

6. Does the patient or do I have wrong expectations of healing?

7. What is the real problem and how can the patient's quality of life be improved by measures other than medical treatment?

In a highly specialized center, the most common diagnostic categories of 193 patients with undiagnosed or difficult-to-manage chronic diarrhea where "low fecal stool weight" syndromes (IBS, hyperdefecation, and fecal incontinence) in $21 \%$, idiopathic secretory diarrhea in $20 \%$, postsurgical (vagotomy, gastrectomy, cholecystectomy, and intestinal resection) in 20\%, microscopic colitis (lymphocytic and collagenous) in 15\%, and "small bowel dysfunction" (small intestinal bacterial overgrowth, carbohydrate malabsorption, diabetes mellitus, motility disorders, strongyloides, sprue, and spruelike illnesses) in 11\% [2].
What Are the Pharmacological Treatment Options in Patients with Chronic Diarrhea?

Table 3 lists pharmacological treatment options for chronic diarrhea, many of them for symptomatic treatment. The symptomatic treatment options shall not delay attention from various additional causal treatment options, like diet in celiac disease or lactose intolerance, or treatments directed against the underlying cause of diarrhea.

\section{Conclusion}

Acute diarrhea is usually of infectious origin with the main treatment goal of preventing water and electrolyte disturbances. In acute diarrhea, signs of potentially invasive bacterial pathogens (fever and bloody stools) shall be observed because these may require antibiotics. In chron- 
ic diarrhea, which is usually not of infectious origin, it is important to identify the underlying cause. Loperamide may be used to decrease stool frequency and improve quality of life. In undiagnosed or intractable diarrhea, the question shall be raised whether the appropriate tests have been performed and interpreted correctly. Some test results may need to be reevaluated.

\section{Conflict of Interest Statement}

The authors have no conflicts of interest to disclose.

\section{Funding Sources}

There was no funding received for research, preparation, and writing of this manuscript.

\section{Author Contributions}

H.H. performed the literature search, collated the information, and wrote the manuscript.

\section{References}

1 Hammer HF. Chronic diarrheal disorders. Preface. Gastroenterol Clin North Am. 2012; 41(3):ix-x.

2 Fine KD, Schiller LR. AGA technical review on the evaluation and management of chronic diarrhea. Gastroenterology. 1999;116(6): 1464-86.

3 Talley NJ, Zinsmeister AR, Van Dyke C, Melton LJ. Epidemiology of colonic symptoms and the irritable bowel syndrome. Gastroenterology. 1991;101(4):927-34.

4 Wenzl HH. Diarrhea in chronic inflammatory bowel diseases. Gastroenterol Clin North Am. 2012;41(3):651-75.

5 Fabian E, Kump P, Krejs GJ. Diarrhea caused by circulating agents. Gastroenterol Clin North Am. 2012;41(3):603-10.

6 Hammer HF, Fine KD, Santa Ana CA, Porter JL, Schiller LR, Fordtran JS. Carbohydrate malabsorption. Its measurement and its contribution to diarrhea. J Clin Invest. 1990; 86(6):1936-44

7 Hammer HF. Pancreatic exocrine insufficiency: diagnostic evaluation and replacement therapy with pancreatic enzymes. Dig Dis. 2010;28(2):339-43.

8 Hammer HF, Hammer J. Diarrhea caused by carbohydrate malabsorption. Gastroenterol Clin North Am. 2012;41(3):611-27.

9 Scaldaferri F, Pizzoferrato M, Pecere S, Forte F, Gasbarrini A. Bacterial flora as a cause or treatment of chronic diarrhea. Gastroenterol Clin North Am. 2012;41(3):581-602.

10 Krones E, Högenauer C. Diarrhea in the immunocompromised patient. Gastroenterol Clin North Am. 2012;41(3):677-701.

11 Tack J. Functional diarrhea. Gastroenterol Clin North Am. 2012;41(3):629-37.

12 Hammer J, Memaran N, Huber WD, Hammer K. Development and validation of the paediatric carbohydrate perception questionnaire (pCPQ), an instrument for the assessment of carbohydrate-induced gastrointestinal symptoms in the paediatric population.
Neurogastroenterol Motil. 2020;32(12): e13934.

13 Hammer J, Sonyi M, Engeber KM, Riedl G, Luong S, Hammer HF. Carbohydrate-induced gastrointestinal symptoms: development and validation of a test-specific symptom questionnaire for an adult population, the adult carbohydrate perception questionnaire. Eur J Gastroenterol Hepatol. 2020;32: 171-7.

14 Hammer HF, Santa Ana CA, Schiller LR, Fordtran JS. Studies of osmotic diarrhea induced in normal subjects by ingestion of polyethylene glycol and lactulose. J Clin Invest. 1989;84(4):1056-62.

15 Pohl D, Fried M, Lawrance D, Beck E, Hammer HF. Multicentre, non-interventional study of the efficacy and tolerability of linaclotide in the treatment of irritable bowel syndrome with constipation in primary, secondary and tertiary centres: the Alpine study. BMJ Open. 2019;9(12):e025627.

16 Hammer HF. Medical complications of bariatric surgery: focus on malabsorption and dumping syndrome. Dig Dis. 2012;30(2): 182-6.

17 Valdovinos MA, Camilleri M, Zimmerman BR. Chronic diarrhea in diabetes mellitus: mechanisms and an approach to diagnosis and treatment. Mayo Clin Proc. 1993;68(7): 691-702.

18 Zhao Q, Hong D, Zheng D, Xiao Y, Wu B. Risk of diarrhea in patients with type 2 diabetes mellitus treated with sitagliptin: a metaanalysis of 30 randomized clinical trials. Drug Des Devel Ther. 2014;8:2283-94.

19 Bricker LA, Such F, Loehrke ME, Kavanaugh $\mathrm{K}$. Intractable diarrhea in hyperthyroidism: management with beta-adrenergic blockade. Endocr Pract. 2001;7(1):28-31.

20 Krejs GJ, Walsh JH, Morawski SG, Fordtran JS. Intractable diarrhea. Intestinal perfusion studies and plasma VIP concentrations in patients with pancreatic cholera syndrome and surreptitious ingestion of laxatives and diuretics. Am J Dig Dis. 1977;22(4):280-92.

21 Kacere RD, Srivatsa SS, Tremaine WJ, Ebnet LE, Batts KP. Chronic diarrhea due to surreptitious use of bisacodyl: case reports and methods for detection. Mayo Clin Proc. 1993; 68(4):355-7.

22 Stepan VM, Hammer HF, Krejs GJ. Hyperkalaemia and diarrhoea in a patient with surreptitious ingestion of potassium sparing diuretics. Eur J Gastroenterol Hepatol. 1997;9(10): $1001-4$.

23 Arasaradnam RP, Brown S, Forbes A, Fox MR, Hungin P, Kelman L, et al. Guidelines for the investigation of chronic diarrhoea in adults: British society of gastroenterology, 3 rd edition. Gut. 2018;67(8):1380-99.

24 Steffer KJ, Santa Ana CA, Cole JA, Fordtran JS. The practical value of comprehensive stool analysis in detecting the cause of idiopathic chronic diarrhea. Gastroenterol Clin North Am. 2012;41(3):539-60

25 Langner C. Colorectal normal histology and histopathologic findings in patients with chronic diarrhea. Gastroenterol Clin North Am. 2012;41(3):561-80.

26 Evans KE, Sanders DS. Celiac disease. Gastroenterol Clin North Am. 2012;41(3):639-50.

27 Hogenauer C, Hammer HF, Krejs GJ, Reisinger EC. Mechanisms and management of antibiotic-associated diarrhea. Clin Infect Dis. 1998;27(4):702-10.

28 Sonyi M, Keller J, Fox M, Hammer HF. Development of a multinational clinical practice guideline: a practical structured procedure. Dig Dis. 2020. doi: 10.1159/000511007.

29 Wenzl HH, Fine KD, Schiller LR, Fordtran JS. Determinants of decreased fecal consistency in patients with diarrhea. Gastroenterology. 1995;108(6):1729-38.

30 Riddle MS, DuPont HL, Connor BA. ACG clinical guideline: diagnosis, treatment, and prevention of acute diarrheal infections in adults. Am J Gastroenterol. 2016;111(5):602-22. 
31 Ropper AH. Campylobacter diarrhea and Guillain-Barré syndrome. Arch Neurol. 1988; 45(6):655-6.

32 Pather $\mathrm{P}$, Hines S. Best practice nursing care for ICU patients with incontinence-associated dermatitis and skin complications resulting from faecal incontinence and diarrhoea. Int J Evid Based Healthc. 2016;14(1):15-23.

33 Fine KD, Seidel RH, Do K. The prevalence, anatomic distribution, and diagnosis of colonic causes of chronic diarrhea. Gastrointest Endosc. 2000;51(3):318-26.

34 Libman M, Catmat. Summary of the committee to advise on tropical medicine and travel (CATMAT) statement on travellers' diarrhea. Can Commun Dis Rep. 2015;41(11):272-84.

35 Whitehead WE, Palsson OS, Feld AD, Levy RL, VON Korff M, Turner MJ, et al. Utility of red flag symptom exclusions in the diagnosis of irritable bowel syndrome. Aliment Pharmacol Ther. 2006;24(1):137-46.
36 Al-Toma A, Volta U, Auricchio R, Castillejo G, Sanders DS, Cellier C, et al. European society for the study of coeliac disease (ESsCD) guideline for coeliac disease and other glutenrelated disorders. United European Gastroenterol J. 2019;7(5):583-613.

37 Ferrari L, Seregni E, Bajetta E, Martinetti A, Bombardieri E. The biological characteristics of chromogranin A and its role as a circulating marker in neuroendocrine tumours. Anticancer Res. 1999;19(4C):3415-27.

38 Lipp RW, Hammer HF, Passath A, Dobnig H, Ramschak-Schwarzer S, Stiegler C, et al. Primary and follow-up studies of patients with carcinoid metastases using indium 111 octreotide-rational use of sandostatin. Acta Med Austriaca. 1993;20(1-2):42-4.

39 Bauckneht M, Albano D, Annunziata S, Santo G, Guglielmo P, Franellizzi V, et al. Somatostatin receptor PET/CT imaging for the detection and staging of pancreatic NET: a systematic review and meta-analysis. Diagnostics. 2020;10(8):598.
40 Tibble J, Teahon K, Thjodleifsson B, Roseth A, Sigthorsson G, Bridger S, et al. A simple method for assessing intestinal inflammation in Crohn's disease. Gut. 2000;47(4):506-13.

41 Melchior C, Aziz M, Aubry T, Gourcerol G, Quillard M, Zalar A, et al. Does calprotectin level identify a subgroup among patients suffering from irritable bowel syndrome? Results of a prospective study. United European Gastroenterol J. 2017;5(2):261-9.

42 Chronic Pancreatitis German Society of Digestive and Metabolic Diseases, Hoffmeister A, Mayerle J, Beglinger C, Büchler MW, Bufler $\mathrm{P}$, et al. [S3-Consensus guidelines on definition, etiology, diagnosis and medical, endoscopic and surgical management of chronic pancreatitis German Society of Digestive and Metabolic Diseases (DGVS)]. Z Gastroenterol. 2012;50(11):1176-224. 